\title{
MEDAL RECIPIENTS
}

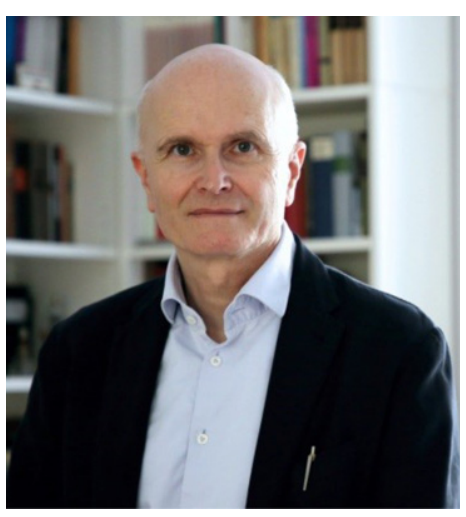

Poiseuille Medal

Axel R. Pries

Professor and Dean, Charité

Universitätsmedizin Berlin

For contributions to hemorheology and remodeling of the microcirculation

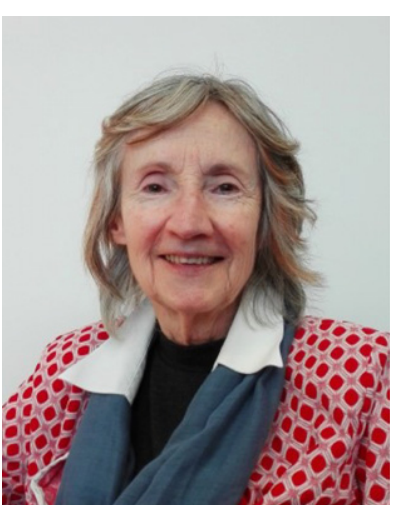

Fåhraeus Medal

Carlota Saldanha

Professor Jubilated, Faculdade de Medicina, Universidade de Lisboa

For studies of rheology of the red blood cell

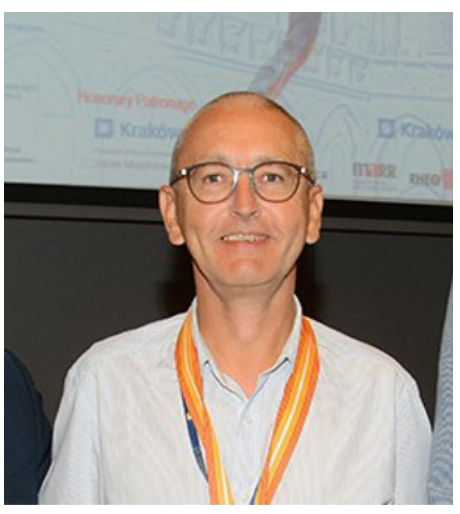

\section{ISCH Medal}

Brian M. Cooke Professor of Microbiology, Monash University

In recognition of outstanding contributions to hemorheology 